\title{
LOS TRIBUNALES CONSTITUCIONALES COMO ÓRGANOS FRONTERIZOS: UNA MIRADA A LA EXPERIENCIA DEL JUEZ CONSTITUCIONAL ITALIANO EN LAS FRONTERAS DE LA VIDA HUMANA'
}

Constitutional courts as frontier institutions: a look at Italian constitutional court's experience about the frontiers of human life

\author{
MARIA PIA IADICICCO \\ Università degli studi della Campania "Luigi Vanvitelli» \\ mariapia.iadicicco@unicampania.it \\ GIUSEPPE LANEVE \\ Università degli studi di Macerata \\ giuseppe.laneve@unimc.it

\section{Resumen}

El presente trabajo propone una reflexión sobre la posición de la Corte Constitucional italiana frente a algunas cuestiones ética y científicamente controvertidas, en particular, la procreación médicamente asistida y el aborto, para comprobar si en este ámbito temático la Corte Constitucional opera efectivamente como «institución

1 El presente trabajo es el fruto de reflexiones compartidas, sin embargo, se deben atribuir a Giuseppe Lavene los parágrafos núms. 1, 2, 3 y 7, y a Maria Pia Iadicicco, los parágrafos núms. 4, 5, y 6. Traducción: Diana Maria Castaño Vargas. 
fronteriza» entre el legislador y los jueces y entre el ordenamiento jurídico interno y externo.

\section{Palabras clave}

Tribunales constitucionales; institución fronteriza; legislatio; iurisdictio; procreación médicamente asistida; aborto.

\section{Abstract}

The aim of this paper is to analyze the attitude of the Italian Constitutional Court regarding some ethically and scientifically controversial issues (birth, abortion, end of life) in order to verify how much the Court confirms to be a «frontier Institution» between legislator and judges and between internal and external legal systems.

\section{Keywords}

Constitutional Courts; frontier Institution; legislatio; iurisdictio; medically assisted procreation; abortion. 


\section{SUMARIO}

I. POLÍTICA Y JURISDICCIÓN DE LOS PROCESOS DE TRANSFORMACIÓN CONSTITUCIONAL. II. EL AVANCE DE LA JURISDICCIÓN. III. SOBRE EL PAPEL DE LA CORTE CONSTITUCIONAL COMO INSTITUCIÓN «FRONTERIZA»: 1. Entre política y jurisdicción. 2. Entre orden interno y orden externo. IV. EL PAPEL DE «INTERMEDIARIO» DE LA CORTE CONSTITUCIONAL EN CUESTIONES BIOJURÍDICAS. V. PRÁCTICAS PROCREATIVAS, DIAGNÓSTICAS Y EXPERIMENTALES SOBRE EL EMBRIÓN HUMANO, ENTRE DERECHO LEGISLATIVO Y JURISPRUDENCIAL. VI. LA CORTE CONSTITUCIONAL EN EL CONTROVERTIDO CASO DEL ABORTO. VII. CONCLUSIONES. BibLIOGRAFÍA.

El objetivo del presente trabajo es analizar la posición de la Corte Constitucional italiana frente a algunas cuestiones ética y científicamente controvertidas con el propósito de comprobar su naturaleza como institución «fronteriza» (Onida, 2006: 533).

Para tal fin, es necesario partir de dos órdenes de consideraciones que conjuntamente trazan el marco de referencia dentro del cual nos moveremos: el primero se centra en la reciente y no poco problemática relación entre el legislador y los jueces; el segundo analiza con más detalle la justicia constitucional y su papel desde una perspectiva que ya no puede ser solo nacional, sino que se abre (en lo que a nosotros respecta) a la dimensión europea.

\section{POLÍTICA Y JURISDICCIÓN DE LOS PROCESOS DE TRANSFORMACIÓN CONSTITUCIONAL}

La relación entre el poder político y el poder jurisdiccional, entre voluntas y ratio, gira alrededor de aquella zona neurálgica del derecho constitucional que se ubica en el punto de intersección entre la forma de gobierno y la forma de Estado, tema clásico del constitucionalismo antiguo y moderno que conoce en los últimos tiempos nuevas declinaciones difícilmente atribuibles a una simple causa, siendo, en cambio, el resultado de dinámicas mucho más complejas, no solamente jurídicas. El contexto en el que hoy se desarrolla el tema está atravesando por procesos de cambio tan radicales que cuestionan seriamente diferentes categorías fundadoras del Estado constitucional, en particular se pueden citar, sin orden de importancia: la nueva relación entre política y economía, el estado de emergencia generado por la crisis financiera 
y por el terrorismo internacional, el progreso de la ciencia y la tecnología, el papel desempeñado por las redes sociales, la imponencia de los flujos migratorios. Procesos que en una compleja y doble relación de causa y efecto se insertan con una fuerza disruptiva en el sistema de representación política, cuya crisis encuentra razones también en otros lugares y en tiempos más lejanos, revelando toda su fragilidad actual (Barbera, 2008; Frosini, 2017; Serges, 2017; Staiano 2017; Ruggeri, 2018).

La globalización en sus múltiples formas de manifestación, todas ellas unidas por la eliminación de las fronteras, ha puesto en crisis un topos del derecho público moderno: la soberanía del Estado, y aunque no ha determinado en sí misma una superación de los Estados nacionales (Cassese, 2017), ha producido profundas transformaciones constitucionales (Morrone, 2016).

Entre los interrogantes más apremiantes de hoy en día se encuentra la búsqueda del sujeto más capaz de asumir —en términos de eficiencia y responsabilidad, sin hacer caso omiso de las conquistas del constitucionalismo- (D’Andrea, 2014) la carga de la decisión pública, dada la evidente erosión de la primacía del legislador.

Por lo tanto, el conflicto entre legis-latio y iuris-dictio no deja de repetirse continuamente, encontrando dinámicas propias que reflejan la eterna tensión instaurada no solo entre la abstracción de la norma y la concreción de los múltiples eventos humanos, sino también a un nivel superior, entre el principio de la legitimidad democrática del poder político y el principio consustancial del constitucionalismo, del límite al primero, que utiliza principalmente el canal jurisdiccional. Se trata de un conflicto -en cierto modo- "fisiológico» del Estado constitucional pluralista y complejo que — no por casualidad, en la búsqueda de una composición equilibrada del mismo- alimenta constantemente los presupuestos de su existencia.

Sin embargo, ha de tenerse en cuenta que el contexto en el cual se «juega el partido» legis-latio y juris-dictio, ha cambiado notablemente en las últimas décadas; con tal propósito es necesario recordar, aunque sea someramente, que aquello que originalmente constituía una relación simple con un desarrollo lineal, casi en sentido vertical entre la ley y la decisión judicial, se ha ido reestructurando paulatinamente en términos mucho más complejos.

Sin ahondar en esta sede sobre los conocidos procesos que han llevado a abandonar la concepción de matriz positivista del siglo Xvin, en la que se consideraba al legislador como omnipotente, se puede observar la aparición de una nueva conciencia hermenéutica que ha desplazado el epicentro de la interpretación en favor de la figura del intérprete y, por lo tanto, in primis, en favor del juez.

Tal reposicionamiento ha encontrado terreno particularmente fértil en la fase evolutiva del Estado constitucional, en la cual la implementación de las constituciones del siglo xIx dio vida, como demuestra la experiencia italiana, a una verdadera transformación constitucional (Fioravanti, 2016). 
En efecto, de la idea de Constitución como loi politique — norma fundamental y superior, pero no inmediatamente preceptiva, sino solamente respecto al legislador, con los jueces relegados, en todo caso, a aplicar (únicamente) la ley - nos hemos alejado precisamente gracias al fundamental aporte ofrecido por la Corte Constitucional desde sus primeras decisiones (núm. 1 de 5 de junio de 1956 y núm. 3 de 15 de junio de 1956), que establecen la superación de la división entre «legalidad constitucional» y «legalidad legal», reconociendo de igual manera a los jueces comunes la facultad de interpretar y aplicar directamente los principios constitucionales (Laneve, 2014).

Esto ha provocado un cambio en la misma configuración del poder: el poder jurisdiccional ha salido del cono de sombra proyectado por el legislador que le impedía «ver» la Constitución y — desde una posición subordinada a este último - se ha eregido hasta ubicarse horizontalmente a su lado. La imagen reflejada cambia: ya no se trata de una línea recta vertical, sino de un esquema triangular en cuya base persisten dos poderes: el del legislador y el del juez, uno al lado del otro, ambos en presencia del vértice representado por la Constitución (Fioravanti, 2016).

Por un lado, tal novedad ha abierto el camino a una interrelación que se esperaba fuera fructífera entre el poder legislativo y el poder judicial en aras de dar "vida real» a la Constitución: el primero a través de la actuación (Modugno, 1970), y el segundo a través de la interpretación/aplicación, ya de la misma Constitución y no solo de lo que ha dispuesto el legislador, guiada por las múltiples virtualidades de los hechos sociales. Por otra parte, esta novedad ha creado las condiciones para que se establezca una potencial relación conflictiva entre ellos, anteriormente ausente o en cualquier caso reducida al mínimo.

Además, situar a los jueces directamente en relación con la Constitución también ha significado preparar el terreno para la aplicación de los principios, in primis, precisamente aquellos constitucionales, cuya carga semántica —orientada axiológicamente hacia un sistema de valores destinado a transformar la estructura social- constituye un rasgo distintivo de las Constituciones de la segunda mitad del siglo Xx. Es precisamente en esta área de principios, y a través de las múltiples trayectorias que se desarrollan en ella, donde la relación entre el poder de la legislatio y iurisdictio corre el riesgo de encontrar las tensiones más fuertes.

En virtud de su componente textual y paratextual (Ruggeri, 2007), la aplicación de los principios propicia la facultad de alejarse de las rígidas reglas del silogismo judicial, dando paso a operaciones cada vez más complejas que inducen con mutable intensidad, dependiendo del órgano judicante y de específicas circunstancias fácticas, a aumentar la dosis de creatividad en la actividad interpretativa-integrativa del derecho por parte del juez (Schmitt, 1978). El mayor grado de indeterminación linguística típica de las normas-principio, en efecto, atenúa ese anclaje textual que ciertamente constituye el método de verificación, y por lo tanto el criterio de legitimidad de la actividad interpretativa (Luciani, 2016a). 
Además, es en el momento en que se recurre a los principios —a través de su composición sistemática y equilibrada - cuando los jueces se enfrentan al carácter ontológicamente incompleto del derecho en cuestión, es decir, a la inevitable incapacidad de abarcar en el tiempo y en el espacio todos los casos de la vida.

Son conocidas sobre este punto las críticas antipositivistas con fundamento en la teoría de Dworkin, por la cual es sobre todo en los llamados casos difíciles, o sea aquellos que no pueden ser decididos simplemente con la aplicación de una regla reconocida, donde se puede observar palmariamente la existencia de un derecho constituido precisamente por principios, los cuales, anteponiéndose a las normas establecidas por el legislador, circunscriben y orientan las decisiones de los jueces.

Es necesario, además, resaltar que cuanto más se amplían los márgenes de maniobra de los jueces, más aumenta el riesgo de ser inducidos a anteponer sus convicciones morales y personales al deber de aplicar las normas jurídicas que son, por cierto, obligatorias (Zanon, 2015).

La problemática en el uso de los principios por parte de los jueces se aprecia aún más cuando se proyecta en dimensión supranacional. En efecto, en el plano del derecho de la Unión Europea, no pocas veces los jueces comunes llevan a cabo la inaplicación de la legislación interna, no solo y siempre en relación con normas europeas específicas, sino tomando como parámetro normas-principio de la Unión (también) abiertas, presentes tanto en los tratados y directivas como en la Carta de Niza, ricas en cláusulas generales, con un bajo nivel de determinación y, como tales, no siempre directamente o al menos inequívocamente aplicables (Barbera, 2018).

\section{EL AVANCE DE LA JURISDICCIÓN}

No cabe duda de que el circuito tradicional de la representación político-parlamentaria está mostrando un considerable estado de debilidad, en parte ocasionado por la acción de los factores de profundo cambio mencionados anteriormente y que se traduce en la insuficiencia por parte de estos para dar respuestas eficaces a las diferentes y complejas demandas provenientes de la sociedad.

Frente a una democracia representativa que se percibe alternativamente como inadecuada o totalmente inútil, se responde, no por casualidad, con la visión salvífica reconocida a la democracia directa (Urbinati, 2013). Si la política es deficiente o se demuestra demasiado débil, el papel de los jueces, especialmente de aquellos de vértice, tiende a adquirir fuerza y autoridad para contrarrestar en nombre de la protección de los derechos fundamentales el grave déficit democrático de algunas decisiones tomadas (Ferrarese, 2010).

Frente a una crisis de representación que, además, no puede reducirse únicamente a la figura del representante, involucrando de hecho —y quizá en 
primera medida - al mismo sujeto representado (Luciani, 2001; Frosini, 2017), se evidencia la imagen de un legislador que renuncia a su papel de mediador de conflictos sociales y que propone, no pocas veces eludiendo una discusión parlamentaria sustancial, soluciones amortiguadoras de emergencia y provisionales, revelándose exactamente lo contrario de lo que debería ser para Gerhart Husserl, es decir, aquel sujeto cuya labor «se refiere al futuro, que el prevé con una anticipación de tipo intelectual», cuya "acción se sustenta en la idea de un futuro predecible, aun calculable» (Husserl, 1955: 50).

El terreno para el poder judicial, por lo tanto, parece bastante fértil (Morrone, 2019). Sin embargo, los motivos no deben reconducirse exclusivamente al atraso o a la «retirada» por parte del poder político. De hecho, hay otras razones más profundas que solo pueden someramente mencionarse aquí.

La falta de confianza en el sistema representativo por parte de una sociedad profundamente desigual se traduce en una confianza (probablemente excesiva) en los jueces, quienes llamados a resolver casos concretos deben ofrecer - además, como hemos visto, pudiendo hacer uso de amplios márgenes de discrecionalidad - una solución case by case a aquellos conflictos entre principios (y valores) sobre los cuales el responsable de la toma de decisiones políticas, a veces intencionadamente, no se pronuncia.

Detrás de la montée en puissance del poder jurisdiccional (Delmas-Marty, 2005-2006) existe, además, una concepción diferente de los derechos y del mismo derecho, que termina siendo entendido como algo que encuentra su razón de ser solo al interior de las aulas de los tribunales. Un derecho creado por casos y que sigue los casos, y que incluso puede llegar a anticiparlos, calificando al juez como verdadero precursor de las nuevas fronteras relacionadas con las necesidades que merecen tutela (Scaccia, 2017). Esto puede configurar el riesgo de tocar derivas en las que se tiende a considerar como derecho toda expectativa (quizá incluso instantánea), toda necesidad e incluso todo deseo en busca de satisfacción (Zanuso, 2015; Pintore, 2017), fuera de cualquier mediación política y construcción legal (Luciani, 2016b).

Esta perspectiva de un constitucionalismo oprimido por los derechos resulta bastante peligrosa, y es síntoma de un retorno cultural de matriz individualista (Laneve, 2018) donde prevalece, a toda costa, la satisfacción de las necesidades del individuo sobre aquellas funcionales a un bien común, aspiración máxima de toda comunidad política (Bilancia, 2017).

Por último, pero no por ello menos importante, es la acción de los jueces (supremos y comunes) quienes dictan constantemente el camino maestro del proceso de integración entre los sistemas jurídicos nacionales y supranacionales. Dirigiendo la mirada en la dirección en la que se entrecruza el flujo del derecho de la Unión Europea y el «derecho» $\mathrm{CEDH}$, una perspectiva que - aunque de enorme importancia - sigue siendo parcial respecto a la presencia de otros flujos practicables en la comunidad internacional, la imagen que emerge es la de un espacio saturado de jueces que - no obstante su heterogeneidad (de grados y naturaleza), y aunque no siempre sigan una lógica libre 
de contradicciones o capaces de evitar conflictos- son los primeros y principales actores en la implementación del derecho de la Unión Europea y del «derecho» $\mathrm{CEDH}$.

A lo largo de canales de comunicación ininterrumpidamente recorridos por una pluralidad de cartas constitucionales, principios, centros de producción de derecho, textos normativos y (sobre todo) una pluralidad de jueces, son estos últimos - antes y más que los sujetos políticos — los que disponen de las herramientas, procedimientos y técnicas para operar como verdaderos cinturones de transmisión (Cassese, 2009; Ferrarese, 2010).

El bosquejo del cuadro en examen es complejo, mutable y esquivo. Más bien propenso a fáciles y peligrosas sobreposiciones. La distinción de los roles entre legislatio y iurisdictio, o sea, los dos soportes sobre los cuales se apoya y sostiene el Estado constitucional, aunque complicada, sigue siendo necesaria, como ha señalado con claridad ejemplar Augusto Barbera: «Una Constitución conserva fuerza y prestigio si los principios constitucionales constituyen no solo la trama y urdimbre para una siempre más rica jurisprudencia, sino también la base para decisiones "fuertes", asumidas por sujetos políticos que expresan la soberanía popular» (2015: 264).

Respecto a la que sigue siendo una dirección de marcha obligatoria, es decir, la protección sistémica de los derechos, el legislador -legitimado por el circuito de la representación democrática- es responsable de la posición (fundamental) de los textos normativos, que deben proponerse cada vez más en términos generales, esenciales y dúctiles; textos construidos de tal manera que, a su vez, "trasciendan» en una tensión dialéctica continua hacia el juez, quien en su posición intermedia específica entre el texto y el contexto fáctico, es responsable de la extrapolación (igualmente fundamental) de la regla del (y en el) texto para resolver el caso concreto (V. Frosini, 1998).

El juez, sin embargo, está destinado a no detener su labor aquí, a nivel del texto legislativo, toda vez que tendrá que recurrir con mayor frecuencia a los sistemas supranacionales para extraer nuevos elementos capaces de integrar y continuamente replasmar la regla que será llamada a aplicar en el caso concreto.

Por lo tanto, se demuestra que el legislador y los jueces son parciales en su producción jurídica, ambos necesitan del otro, y ambos, al final, no son individualmente suficientes para el mantenimiento de la democracia constitucional.

\section{SOBRE EL PAPEL DE LA CORTE CONSTITUCIONAL COMO INSTITUCIÓN «FRONTERIZA»}

\section{ENTRE POLÍTICA Y JURISDICCIÓN}

Pasando ahora al segundo orden de consideraciones contextuales y focalizando la mirada en los órganos nacionales de justicia constitucional, no 
podemos pasar por alto que estos, llamados a ejercer la función que marcó un hito en el siglo Xx — la de someter la entera dimensión de los poderes públicos al respeto de la supremacía de la Constitución y de sus principios-, habitan naturalmente en un espacio infranqueable entre la política y la jurisdicción.

La afirmación se puede declinar en diferentes niveles, aunque después podrían confluir en una única síntesis, como lo demuestra perfectamente la experiencia italiana. Significa, como primera medida, que la Corte Constitucional se sitúa funcionalmente entre el poder político y el poder jurisdiccional, así mismo denota que la revisión constitucional de las normas (su principal campo de acción), puede tener también como objeto el acto político por excelencia, la ley, solamente a través de la intermediación de cualquier otro juez pasando por un caso de la vida y siguiendo las formas y procedimientos propios de la jurisdicción. Significa, además, que en la composición de la Corte se garantiza un equilibrio entre los miembros de extracción política, elegidos por el Parlamento en sesión conjunta y con mayoría cualificada, y los miembros de extracción judicial.

La síntesis está en concebir la Corte Constitucional como una verdadera institución «fronteriza», por lo que cada decisión que toma - especialmente en el juicio respecto a las leyes, así como en las sentencias que deciden sobre conflictos entre poderes del Estado, entre Estado-región $y$ en aquellos sobre referendos- produce efectos de gran alcance, que encuentran su fundamento en el caso que se somete a su juicio, pero cuya incidencia no se agota en él. Los efectos de las sentencias de la Corte tienen su origen en el caso concreto, pero se proyectan en el sistema entero, repercutiendo algunas veces en la forma de gobierno, otras veces, en la forma del Estado, o en ambas. La Corte, con sus decisiones, resuelve el caso, pero (simultáneamente) «impacta en el sistema» (Bognetti, 1990: 231-2).

Esta es en esencia la diferencia sustancial que aún existe entre los tribunales constitucionales (nacionales) y los tribunales europeos (supranacionales): si estos últimos operan en un entorno sin legislador, Estado ni Constitución (al menos en la concepción tradicional de dichos términos), y además pueden aspirar a ejercer una actividad jurisdiccional neutral, es decir, no (demasiado) condicionada por lo político, solamente los tribunales constitucionales actúan en un espacio condicionado por la inmanencia de la forma de gobierno y se ven afectados precisamente por los límites derivados del tener que insertarse en un sistema de equilibrios institucionales que ellos mismos, con cada decisión, contribuyen constantemente a perfeccionar (Scaccia, 2017a).

Esta posición específica y aun única tiene un impacto determinante en el enfoque que los tribunales constitucionales tienen respecto a las diferentes cuestiones y, por lo tanto, sobre las técnicas de ponderación, equilibrio, argumentación y toma de decisiones utilizadas por ellos. La politicidad del objeto de las decisiones debe equilibrarse con la jurisdiccionalidad de las reglas procesales a las que los tribunales deben ceñirse (Romboli, 2017). 
Precisamente la ardua y continua búsqueda de un punto de equilibrio se refleja en la forma de operar de los tribunales que, no por casualidad, en el curso de sus juicios, frente a dos o más intereses constitucionales en juego (excepto en muy raras ocasiones), en lugar de elegir uno y "cercenar» los otros, recurre a un paradigma mucho más complejo: el de balancear y ponderar.

Tal paradigma, según lo declarado por la Corte Constitucional italiana en la Sentencia de 28 de noviembre de 2012, núm. 264, también tiene relevancia a nivel de las relaciones entre el ordenamiento constitucional y el «ordenamiento» CEDH: la «máxima expansión de las garantías» de los derechos incluye en sí misma «el balance necesario con otros intereses constitucionalmente protegidos, es decir, con otras normas constitucionales que a su vez garantizan derechos fundamentales que podrían verse afectados por la expansión de una tutela individual». Por lo tanto,

\begin{abstract}
el llamado al «margen de apreciación» nacional —elaborado por el mismo Tribunal de Estrasburgo, relevante en cuanto atemperante de la rigidez de los principios formulados en sede europea-, debe estar siempre presente en las evaluaciones de los diferentes tribunales constitucionales, «quienes no olvidan que la tutela de los derechos fundamentales debe ser sistémica y no fraccionada en una serie de normas descoordinadas y potencialmente en conflicto entre ellas.
\end{abstract}

\title{
2. ENTRE ORDEN INTERNO Y ORDEN EXTERNO
}

Razonar sobre la justicia constitucional hoy en día significa abordar el rasgo que más ha caracterizado su desarrollo en esta primera parte del siglo, es decir, su continua y estable proyección supranacional. El fenómeno es en general reciente y, como tal, ciertamente no se encuentra maduro para juicios definitivos. Sin embargo, los no pocos pronunciamientos de los diferentes tribunales constitucionales europeos (y de los tribunales europeos) dictan valiosas indicaciones para realizar algunas consideraciones provisionales.

La primera consideración hace referencia a la superación de las fronteras, lo cual parece constituir una nueva guarnición protectora de la jurisdiccionalidad de los tribunales constitucionales.

De hecho, en la nueva dimensión, es realmente difícil para los tribunales seguir considerándose y operar como órganos «de cierre», debiendo, por el contrario, reproponerse en un escenario relacional con múltiples interlocutores, como los canales de comunicación más autorizados y la sede de elaboración e intercambio de materiales supremamente valiosos, que encuentran aplicación en la riqueza de los procesos interpretativos de las cartas constitucionales.

La circulación y recirculación de materiales entre tribunales (no todos de la misma naturaleza, pero sí de igual rango) y entre cartas constitucionales constituye un laberinto impenetrable dentro del cual, sin embargo, la brújula 
más eficaz parece estar en manos de los tribunales constitucionales nacionales, principalmente en virtud de sus técnicas exclusivas de juicio.

Tal proyección supraestatal de los tribunales y tal puesta en circulación, de hecho, representan la mejor garantía de jurisdiccionalidad para cada órgano de justicia constitucional y, para sus juicios, una garantía que radica (en términos alegóricos) «en la voluntad de cuestionarse a sí mismo, de jugar [...] el partido en pie de igualdad, dejando a un lado el cetro del soberano quien, en celosa pero angustiosa soledad, puede y debe, en última instancia, decidir por todos o sobre todos» (Ruggeri, 2011:372).

La segunda consideración hace referencia al papel de los tribunales constitucionales en relación con el derecho de la Unión Europea, el cual no se reduce a la mera función — aunque fundamental — de «ambientación» dentro del respectivo ordenamiento de principios, tal vez formados de manera compleja y coordinada a nivel supranacional; ni tampoco se reduce a la función de guardianes últimos - en sentido opositor- de los principios constitucionales supremos de los ordenamientos nacionales. Su papel es necesariamente aún más complejo: de hecho, y estamos ya en la tercera consideración, sustancialmente concurren con el respeto de sus respectivos roles, excluyendo algunos forzamientos, a la formación del derecho europeo, siguiendo un enfoque auténticamente dialógico que, como ya oportunamente señalado, no significa renunciar a proponer lecturas alternativas e incluso contradictorias respecto a las interpretaciones hechas por el Tribunal de Justicia de la Unión Europea (Longo, 2017).

En otro orden de ideas, también en el reciente caso Taricco, el juez de Luxemburgo (Sentencia de 5 de diciembre de 2017, causa C-42/17, Gran Sala) pudo reconsiderar el alcance de su primer pronunciamiento (Sentencia de 8 de septiembre de 2015, causa C-105/14, Gran Sala) a la luz precisamente de las nuevas radiaciones semánticas transmitidas por la Ordenanza de 26 de enero de 2017, núm. 24, de la Corte Constitucional italiana, relativas a los principios constitutivos, no solo del ordenamiento nacional, sino también europeo. Con esto se revela otro perfil de interés, especialmente en una perspectiva del diálogo entre tribunales, donde lo más importante no es, como se acaba de ver, tener una (ilusoria) última palabra, sino quién tiene la primera palabra, pero no para establecer una (igualmente ilusoria y dañina) primacía entre los tribunales, sino para predeterminar la prospectiva de la cuestión de derecho de la Unión Europea.

Por otra parte, la posición firme y decidida de la Corte italiana de reivindicar para sí misma la función tendiente a «determinar si el derecho de la Unión Europea está en contraste con los principios supremos del orden constitucional y, en particular, con los derechos inalienables de la persona» parece seguir esta misma dirección en otro pronunciamiento igualmente famoso, la Sentencia de 7 de noviembre de 2017, núm. 269, en la cual se estableció una especie de prioridad de la cuestión de legitimidad constitucional sobre la prejudicial comunitaria, en el momento en que el juez común sospeche la 
ilegitimidad de una ley por contraste tanto con los derechos protegidos por la Constitución como con aquellos garantizados por la Carta de Derechos fundamentales de la Unión Europea.

Aunque la trayectoria trazada por tal sentencia requiere más que nunca aclaraciones adicionales, como lo demuestran algunas decisiones posteriores de los jueces comunes y del propio juez constitucional (Sentencia de 23 de enero de 2019, núm. 20), este último parece interesado en preservar hasta el final su rol en la elaboración también del derecho de la Unión Europea, en el cual la misma identidad constitucional, en lugar de ser un fantasma opositor, puede ser vista por el Tribunal de Justicia de la Unión Europea como una coordenada fundamental en la dinámica interpretativa (Scaccia, 2017b).

Con tal modo de actuar y operar - tras las aclaraciones y ajustes necesarios-, los tribunales constitucionales se convierten en verdaderos jueces europeos capaces de transmitir a los tribunales europeos (en forma más adecuada) las exigencias y las posiciones nacionales en términos de tradiciones constitucionales y de margen de apreciación nacional.

En una mirada más atenta, la naturaleza de los tribunales constitucionales como órganos fronterizos reaparece en un ulterior y nuevo lugar, ahora se encuentra también presente entre el orden interno y los órdenes supranacionales.

Si se analizan detenidamente estas posiciones adquieren además un peso específico a nivel interno, repercutiendo significativamente en la relación entre el juez constitucional y los jueces comunes: desde el punto de vista de la salvaguardia del juicio concentrado de constitucionalidad — cuyo riesgo de erosión, ya experimentado en relación con el deber de interpretación conforme, puede repetirse a la luz de desaplicaciones demasiado desenvueltas, es decir, del recurso prevalente al reenvío prejudicial que concretizaría un hilo (demasiado) directo entre jueces comunes y Tribunal de Justicia-, la Corte Constitucional italiana insiste en su facultad de poder intervenir cada vez que estén en juego principios fundamentales y derechos inviolables de la Constitución. Un modo este para evitar forzamientos excesivos por parte de los jueces comunes y para afirmar su rol en un nuevo contexto: en resumen, para redefinir un nuevo punto de equilibrio en la dinámica entre poderes (Laneve, 2018).

\section{EL PAPEL DE «INTERMEDIARIO» DE LA CORTE CONSTITUCIONAL EN CUESTIONES BIOJURÍDICAS}

Las consideraciones hechas hasta ahora sobre la relación entre legislatio y iuris-dictio y, en particular, sobre la posición intermedia mantenida, incluso en la relación entre lo interno-externo por la Corte Constitucional, se reflejan claramente en el desarrollo concreto de algunos acontecimientos 
relacionados con la vida humana, con su inicio (procreación y nacimiento), con su desarrollo, hasta su deceso (muerte).

Es indispensable reiterar que las dinámicas relativas a la mencionada relación repercuten plenamente en la experiencia jurídica, tocando los aspectos más esenciales y sus puntos más neurálgicos, motivo por el cual —no obstante sean pertinentes - las investigaciones parciales y limitadas a áreas específicas son desaconsejables. Sin embargo, la delimitación aquí propuesta se revela de particular importancia y se encuentra justificada por una serie de motivos.

Las cuestiones precedentemente citadas, habida consideración de su incidencia en los principios, derechos y deberes constitucionales, obligan a evaluar su resistencia frente a decisiones políticas (de intervención o abstención) y frente a prácticas jurisprudenciales, que — de igual manera- pueden trascender las fronteras del ordenamiento jurídico nacional, coadyuvadas por las ciencias y las biotecnologías con una vocación intrínsecamente no territorial.

En tal sentido, también en este delicado ámbito, el juez constitucional a menudo se encuentra llamado en causa para verificar la razonabilidad de la ponderación entre intereses constitucionales en conflicto, efectuada por los órganos político-representativos o, por estos intencional o imprudentemente, dejada de efectuar (D'Aloia, 2005: XV); no obstante, es tal vez en esta sede, en donde se presenta - con mayor frecuencia respecto a otros sectores de la experiencia social - que la composición entre instancias de relevancia constitucional se confíe a una interrelación sinérgica y virtuosa entre todos los actores institucionales (D'Andrea, 2017: 22-23). No cabe duda, en efecto, de que a nivel constitucional se encuentren igualmente normas (principios y reglas) relevantes en estos ámbitos — circunstancia que es aún más irrefutable dada la "envergadura» de los bienes jurídicos involucrados-, sin embargo, la concretización de estas normas difícilmente se reduce a su integral aplicación o violación o, en todo caso, en procesos de composición preestablecidos que no impliquen elecciones con un alto contenido político.

Por lo tanto, es en este escenario en el que los parámetros constitucionales involucrados se prestan a interpretaciones y aplicaciones variables (Casonato, 2012: 154), en donde se determinan, quizá más que en cualquier otra sede, considerables fluctuaciones entre las dos almas coexistentes de la Corte Constitucional: la política y la jurisdiccional.

Sin perjuicio de la inevitable politicidad de cualquier juicio sobre la ponderación razonable de intereses constitucionales, el papel de "cierre» desempeñado por los tribunales supremos y, en específico, respecto al ordenamiento italiano de la Corte Constitucional, no es suficiente por sí solo para asegurar una efectiva garantía de los derechos constitucionales en cuestión, requiriéndose, así mismo, intervenciones de actuación política mucho más complejas que la simple aplicación de la norma constitucional al caso concreto. 
Las tareas encomendadas a los actores institucionales, específicamente sobre estos temas, se dificultan aún más por su acentuada complejidad, producto tanto de su particular vena ética como de su innegable connotación científica. De modo que las cuestiones planteadas no solo afectan el ya delicado equilibrio entre política y jurisdicción, sino que también afectan las posiciones que cada uno de ellos está llamado a asumir, ya sea en relación con múltiples concepciones éticas (lo cual hace que no sea fácil identificar una conciencia social precisa) o en relación con las ciencias y técnicas biomédicas, cuyas adquisiciones o aplicaciones podrían ser consideradas a su vez como objeto de reglamentación y como parámetro de la misma.

Pues bien, frente a similares cuestiones, a la vez éticamente sensibles y científicamente connotadas, no es raro encontrar reconstrucciones que consideran preferible la retracción de la decisión pública en favor de la autonomía de la voluntad del sujeto en cuestión o de la autorregulación de los organismos científicos, cuya competencia técnico-especialista permitiría así vencer la prolijidad (y la falta de conclusión) de los debates y procedimientos del órgano de representación política.

De hecho, en los casos examinados, tal perspectiva no es menos falaz, no solo porque la falta de reglamentación jurídica sea suficiente para excluir el conflicto entre portadores de intereses contrapuestos, destinados inevitablemente a desembocar en el canal jurisdiccional, sino también porque parece desatender las exigencias publicísticas subyacentes a una regulación que, no obstante incide en cuestiones existenciales de la persona humana, pone de relieve la dimensión comunitaria de la misma, la condición del homme situé, asumida en la concreción de sus necesidades que, sin embargo, opera y pertenece a una comunidad política.

Asimismo, tampoco ha de pasarse por alto que, como ya se ha mencionado, especialmente en cuestiones relacionadas con la vida humana, se revela una tensión más marcada entre la abstracción propia de la norma jurídica y la concreción de las múltiples vicisitudes existenciales. Serían sobre todo estos hard cases, en los cuales se tiene por objeto derechos fundamentales, deducibles de disposiciones de principio enunciadas con fórmulas vagas, con una connotación evaluativa, y cuyo contenido no cuenta con un consenso generalizado, a poner en primera línea el derecho jurisprudencial, in primis, el juez común, quien según el ordenamiento italiano está obligado a decidir incluso en ausencia de una ley, no obstante el principio de sujeción (solamente) a la ley (art. 101.2 Const.), teniendo que adaptar la norma legislativa, si existe, a la singularidad del caso concreto, permitiendo su «corrección» mediante interpretaciones conformes a la Constitución, así como comunitaria y convencionalmente orientadas o, al contrario, cuando no fuese posible, a través del envío de las cuestiones de constitucionalidad a la Corte Constitucional.

La evidente, aunque indefinida, dimensión constitucional de las cuestiones vinculadas con la vida de la persona humana se nutre, por tanto, de la continua 
confrontación entre legis-latio y iuris-dictio, que bien puede traducirse en una presión ejercida por el juez, incluido el constitucional sobre el legislador con el fin de estimularlo a tomar decisiones políticas sobre tales cuestiones, o bien traducirse en una reacción jurisprudencial a específicas reglamentaciones legislativas, o incluso, en una suplencia ambigua del juez respecto al legislador, ambigua no solo porque el mismo concepto de suplencia se presta a diferentes claves de lectura, sino porque tal suplencia puede ser percibida como algo necesario e inevitable, como algo que se debe soportar o como algo inconveniente, pero igualmente necesario.

Permaneciendo solo en el ámbito de las cuestiones bioéticas fundamentales, los casos a los que se puede hacer referencia para dar testimonio de esta confrontación hecha de persecuciones, contrastes y/o, en todo caso, reenvíos mutuos entre legisladores y jueces, Corte Constitucional y tribunales europeos, son realmente numerosos; limitándonos aquí solamente a los casos más conocidos y controvertidos que han animado un rico debate en la experiencia jurídica italiana, comparable al que se está produciendo en muchos otros países.

Podemos hacer referencia entonces a los casos relacionados con las técnicas de procreación médicamente asistida (PMA), el diagnóstico genético preimplantacional, la experimentación embrionaria, el conocimiento del origen biológico en caso de parto anónimo o fecundación heteróloga, la interrupción voluntaria del embarazo, el transexualismo, las relaciones familiares, el matrimonio homosexual, la atribución del apellido materno, la eutanasia pasiva y activa.

Entre estos casos, que ciertamente no agotan el vasto campo de experiencias existenciales de la persona humana, solo se examinarán aquellos que tocan directamente uno de los dos extremos (el comienzo de la vida), para verificar cómo se ha expresado al respecto la Corte Constitucional italiana, confrontándose de esta manera con el legislador, los jueces comunes, las cartas europeas de derechos y los respectivos tribunales. Es importante, de igual manera, hacer al menos una mención del otro extremo, es decir, aquel relacionado con el final de la vida (Arruego, 2019), un tema sumamente complejo sobre el cual la Corte Constitucional se ha pronunciado recientemente con una decisión muy debatida (Ordenanza de 24 de octubre de 2018, núm. 207), no solo debido a la extrema delicadeza de la cuestión tratada específicamente (asistencia al suicidio), sino también debido a la técnica de toma de decisiones sin precedentes utilizada por el juez constitucional, que, sin ninguna otra consideración, demuestra, de una parte, la necesidad de una intervención legislativa y, de otra, la insuficiencia de la misma decisión judicial. 


\section{PRÁCTICAS PROCREATIVAS, DIAGNÓSTICAS Y EXPERIMENTALES SOBRE EL EMBRIÓN HUMANO, ENTRE DERECHO LEGISLATIVO Y JURISPRUDENCIAL}

Tomamos como referencia la experiencia de la procreación médicamente asistida (PMA), que ha encontrado una regulación tardía muy discutida, en la Ley de 19 de febrero de 2004, núm. 40, objeto de múltiples pronunciamientos del juez constitucional. Se considera oportuno partir de este caso, no porque sea el que en términos cronológicos traspasó por primera vez las puertas de la Corte Constitucional (mucho antes y en varias ocasiones había ya intervenido en materia de aborto), sino porque, en este caso, la intervención legislativa ha colmado efectivamente una laguna en la materia de qua, una situación de "carencia [...] con implicaciones constitucionales», tal y como la definió la Corte Constitucional en la Sentencia de 22 de septiembre de 1998, núm. 347 , determinada por la especificidad de las condiciones en las que surge la generación humana, consentida y favorecida por los imponentes desarrollos de la ciencia y de la tecnología biomédica.

Pero, sobre todo, la historia jurídica de la PMA en Italia ha sido considerada emblemática por un "cierto modo de estructurar las relaciones entre legisladores, jueces y Cortes» (Tripodina, 2012), «metáfora de la relación atormentada» entre la ciencia jurídica y la ciencia biomédica (Chieffi, 2018), microcosmos del constitucionalismo contemporáneo y de algunas de sus dinámicas peculiares que tocan los nudos fundamentales de la interpretación constitucional y la relación entre la discrecionalidad del legislador y el rol de la Corte Constitucional (D’Amico, 2017: 36).

A partir de una lectura integral del dato legislativo, emerge claramente que el enfoque de fondo adoptado por el legislador italiano en 2004 para regular las prácticas de PMA ha sido aquel de imponer límites rigurosos y verdaderas prohibiciones respecto a las prácticas biomédicas y de predisponer un fuerte sistema de garantías en favor del concebido, «sujeto» débil involucrado en estas prácticas, cuyos intereses, no mejor especificados, se pondrían en estridente contraste con aquellos de quienes aspiran a ser padres.

Se trata evidentemente de un preciso enfoque ideológico —con cierta aproximación podríamos definir prolife - que no es exhaustivo en sí, tratándose de una mera opción interpretativa que bien puede encontrar cabida en la Carta constitucional, sin embargo, esta no tiene en cuenta de la existencia de otras concepciones y, sobre todo, de otros bienes e intereses constitucionales involucrados.

En particular, algunas disposiciones de la Ley núm. 40, en su formulación original, prefiguraban la prevalencia del interés del embrión sobre el derecho a la salud de la madre, quien, necesariamente, debía acogerlo en su propio cuerpo a fin de completar el proyecto de vida, toda vez que, entre otras cosas, la gestación por sustitución está prohibida. 
De hecho, al prohibir la revocación del consentimiento al tratamiento después de la fecundación del óvulo (art. 6, párr. 3) y al admitir la suspensión de la transferencia al útero de los embriones creados in vitro solo por «causa grave y documentada de fuerza mayor, relacionada con el estado de salud de la mujer no previsible en el momento de la fecundación» (art. 14, párr. 3), la Ley núm. 40 ha terminado por ignorar la «incidencia, si no exclusiva, seguramente prevaleciente, del estado de gravidez sobre la salud sea física o mental de la mujer» (Ordenanza de 23 de marzo de 1988, núm. 389). Además, para evitar el recurso sistemático de la sobreproducción de embriones, con sucesiva criopreservación de aquellos no transferidos, el art. 14 de la Ley núm. 40 imponía al médico la producción hasta un máximo de tres embriones con los cuales debía proceder con una única y contemporánea implantación, incluso en los casos en que la ciencia médica más acreditada hubiera sugerido la transferencia gradual de los mismos o una mayor producción de embriones.

Precisamente sobre tal argumento se adoptó la primera decisión modificadora de la Ley por parte de la Corte Constitucional, Sentencia de 8 de mayo de 2009, núm. 151, cuyos argumentos retoman la línea jurisprudencial consolidada respecto a la relación entre discrecionalidad legislativa y autonomía de la ciencia médica, en vista del objetivo fundamental de reconducir a criterios de razonabilidad la ponderación entre los intereses del embrión y el derecho a la salud de la madre, conscientes de que la tutela del primero no puede ser absoluta y, por el contrario, puede estar sujeta a las limitaciones necesarias para salvaguardar la salud de la mujer.

En tal sentido, la mencionada sentencia no solo ha establecido que la decisión a tomarse - caso por caso y en función de las condiciones clínicas de la paciente sometida a la PMA - deba tener en cuenta la prudente y competente evaluación médica sobre el número de embriones a producir, implantar y posiblemente criopreservar, sino que también tuvo el mérito de poner en la justa perspectiva la relación madre-embrión, evidenciando que la salvaguarda de la salud de la primera constituya un requisito indispensable para el éxito del proyecto procreativo y, por lo tanto, también para la satisfacción del derecho a la vida del embrión.

Este argumento se retoma y desarrolla en la sucesiva Sentencia de 5 de junio de 2015, núm. 96, por la que la Corte Constitucional declaró la ilegitimidad constitucional de los arts. 1 y 4 de la Ley núm. 40 de 2004, en la parte en que prohibía el acceso a la PMA a las parejas fértiles, pero portadoras de enfermedades genéticamente transmisibles, interesadas, por tanto, en recurrir a esta práctica, no para superar problemas de esterilidad o infertilidad, sino para practicar exámenes diagnósticos sobre el embrión producido in vitro $\mathrm{y}$, dependiendo de su resultado, poder evitar la transferencia de embriones enfermos.

Se trata de una decisión muy esperada por varias razones: en primer lugar, la Ley núm. 40, no obstante se encuentre saturada de límites claros y rigurosos, no prohíbe expresamente la practicabilidad del diagnóstico genético 
preimplantacional (DGP), difundido en la praxis médica antes de la intervención del legislador del 2004 con fines distintos de la selección eugenésica de embriones, cuando dicha solicitud provenga de sujetos infértiles; en segundo lugar, precisamente sobre esta cuestión, la Corte Constitucional, con la Ordenanza de 24 de octubre de 2006, núm. 369, había considerado, sin entrar en el fondo del asunto, que no podía pronunciarse por vicios procedimentales, allanando así el camino para interpretaciones conformes a la Constitución de disposiciones legislativas por parte de los jueces comunes, interpretaciones de todas formas no consolidadas y, a veces, materializadas en verdaderas desaplicaciones de la ley; en tercer lugar, sobre el mismo caso el Tribunal Europeo de Derechos Humanos (Costa y Pavanc v. Italia, Sentencia de 28 de agosto de 2012) intervino condenando a Italia por violar el art. 8 del CEDH.

En línea de sustancial continuidad con los hallazgos del juez del Tribunal $\mathrm{EDH}$, pero sin usar el parámetro convencional —en un límite entre lo interno y lo externo formalmente demarcado, pero sustancialmente poroso-, la Corte ha reconocido que la prohibición absoluta de acceso a la PMA con diagnóstico preimplantacional por parte de parejas portadoras de enfermedades transmitidas genéticamente constituye un vicio de irracionalidad sistemática de la Ley núm. 40/04 que se identifica a partir de la comparación entre las reglas de esta y las de la Ley de 22 de mayo de 1978, núm. 194, que permite a las mismas parejas que están excluidas del diagnóstico y de la selección preimplantacional, recurrir posteriormente al aborto terapéutico con un evidente mayor perjuicio para la salud de la mujer, constreñida a someterse, para evitar dar a luz a un hijo afectado con la misma patología hereditaria de la que ella o su pareja son portadores, a un tratamiento médico denominado interrupción voluntaria del embarazo (IVE) «innegablemente más traumático» que la selección previa a la implantación y que, en cualquier caso, es inadecuado para proteger al nasciturus.

Una vez que la funcionalidad de las pruebas diagnósticas preimplantatorias para la solución de problemas de salud, especialmente de la mujer, ha sido reconocida en la Sentencia núm. 96/2015, la Corte también se ha preocupado por salvaguardar los intereses constitucionales del nasciturus, de un lado, precisando que la determinación de las patologías hereditarias debe tener lugar en específicas estructuras públicas especializadas y, del otro, instando al legislador a determinar, con base en la evolución técnico-científica, qué patologías graves genéticamente transmisibles pueden legitimar la solicitud de práctica del diagnóstico preimplantacional. Con tal decisión se puede observar, una vez más, la necesidad de adoptar nuevas decisiones en las sedes políticas competentes con base en datos científicamente comprobados, así como la insuficiencia de una tutela circunscrita a la sola en sede jurisdiccional.

En materia de PMA, la decisión seguramente más incisiva, y también por esta razón objeto de observaciones críticas, está ciertamente representada 
por la Sentencia de 10 de junio de 2014, núm. 162, por la que la Corte Constitucional anuló la prohibición absoluta de la fecundación mediante el uso de gametos externos a la pareja aspirantes a convertirse en padres, sobre la cual, de igual manera, se había pronunciado el Tribunal EDH en dos diferentes decisiones (S.H. c. Austria, I Sección, Sentencia de 1 de abril de 2010; Gran Sala, Sentencia de 3 de noviembre de 2011), aunque estas sentencias estaban relacionadas con la prohibición menos estricta vigente en Austria.

A juicio de la Corte Constitucional italiana, el legislador de 2004 —al introducir la prohibición en cuestión - habría sacrificado excesivamente tanto la libertad de los miembros de la pareja de autodeterminarse respecto a la elección de ser padres - libertad que la Corte considera incoercible incluso cuando se ejerce mediante el recurso de las técnicas de PMA de tipo heterólogo- como su derecho a la salud, que debe entenderse «en el sentido propio del artículo 32 de la Constitución, esto es, considerando en igual medida la salud mental como la física». Si respecto a la incidencia en la salud de los miembros de la pareja, el juez constitucional no consideró dirimente las diferencias entre PMA homóloga y heteróloga, sí se preocupó por precisar que la prohibición en cuestión no podía estar justificada por la exigencia de salvaguardar otros preeminentes intereses constitucionales del hijo nacido a través de tal método: entre ellos, no puede presumirse un derecho a la (sola) «genitorialidad biológica», en cuanto la noción de filiación tomada por el ordenamiento jurídico italiano prescinde del dato genético, como puede deducirse fácilmente teniendo en cuenta el instituto de la adopción y la importancia asumida por la «genitorialidad social»; la prohibición tampoco estaría justificada por la necesidad de evitar fines eugenéticos ilegítimos o mayores riesgos para la salud del que está por nacer.

Al mismo tiempo, la Corte ha advertido que el recurso a la PMA con la donación de gametos no puede frustrar el derecho del nasciturus a conocer su identidad genética y, por lo tanto, la regla del anonimato de la identidad de los donantes de gametos debe encontrar un límite justificado en la creación de formas de trazabilidad de estos, tendentes a asegurar el derecho del nacido a conocer su origen biológico, al menos cuando sea necesario resolver un problema de salud.

El reconocimiento del derecho de acceso a la información relativa al propio origen (como aspecto crucial de la propia identidad personal) constituye, además, un tema central que afecta a diferentes ámbitos materiales y que, en un círculo virtuoso activado entre legisladores y jueces ${ }^{2}$ incluido el constitucional, ha consentido progresivamente la eliminación de las prohibiciones preexistentes y la expansión del principio de favor veritatis.

2 Obsérvense las reformas del 2001 y del 2013 de la ley sobre la adopción, Ley núm. 184 de 1983. 
Incluso en el caso del parto anónimo - donde el derecho del nacido a conocer su origen biológico ha sido sacrificado (art. 28, párr. 7, Ley núm. 184/83) en aras de salvaguardar de un lado a la mujer, consintiéndole dar a luz en condiciones de seguridad y, del otro, al nasciturus, en cuanto se prevendría el recurso al aborto o inclusive el infanticidio-, después de una importante decisión de la Corte Constitucional (Sentencia de 18 noviembre de 2013, núm. 278), precedida a su vez por la condena de Italia por violación del art. 8 del CEDH (Godelli c. Italia, Sentencia de 25 de septiembre de 2012), la prohibición de conocer los orígenes biológicos ha sido atenuada, reconociendo al menor el derecho a interpelar, en vía reservada y a través de autoridad judicial, la madre biológica con la finalidad de verificar si persiste la voluntad de permanecer en anonimato.

El incumplimiento del legislativo respecto al pronunciamiento en objeto, es decir, la falta de reglamentación del mecanismo de interpelación, ha planteado no pocos problemas interpretativos y aplicativos reflejados en la jurisprudencia, la cual ha expresado posiciones muy contrastantes, en gran parte (aunque no totalmente) superadas por la intervención de la Corte Suprema de Casación en Secciones Unidas (Sentencia de 25 de enero de 2017, núm. 1946), según la cual, incluso en ausencia de la intervención del legislador, el juez está obligado a buscar —en forma objetiva y no de modo deliberado- datos normativos capaces de conciliar los derechos de todos las sujetos implicados, las reglas preexistentes y el principio enunciado por la Corte Constitucional en la sentencia de 2013.

Retomando el tema de la fecundación con donación de gametos —en la que el derecho a conocer sus orígenes biológicos ha encontrado un reconocimiento tardío y solo parcial, en gran parte debido no a la delicadeza del equilibrio entre intereses constitucionales implicados, sino a una persistente aversión ideológica respecto a esta práctica procreativa-, no se puede, sin embargo, pasar por alto algunas observaciones críticas formuladas por una parte de la doctrina sobre la Sentencia núm. 162/2014 y que se refieren a la evaluación de los vínculos y condicionamientos que surgen de tal decisión respecto a las decisiones políticas, expresión de la discrecionalidad legislativa. La preocupación de fondo se refiere a la posible aparición de una concepción de los derechos constitucionales fuertemente dependiente de las adquisiciones de la ciencia y de la tecnología, de modo que todo lo que fuera técnicamente posible constituiría, por lo tanto, un derecho merecedor de la más amplia y necesaria tutela por parte del ordenamiento jurídico (Morrone, 2014).

En efecto, no se puede negar que la Sentencia núm. 162/2014 se distingue respecto a todas las otras sentencias sobre el tema, por una ampliación significativa del concepto constitucional de salud, sin embargo, la Corte Constitucional no pareció subestimar los riesgos que podría provocar la inclinación hacia concepciones subjetivistas y hedonistas de este. Toda la trayectoria argumentativa del juez de las leyes se ha articulado en torno a la necesidad de salvaguardar el derecho a la salud de los aspirantes a ser padres 
y de conciliarlo con las exigencias de la vida naciente. Sin embargo, la efectividad de estos derechos no puede descender únicamente del pronunciamiento de la Corte, presuponiendo, en cambio, una intervención de las autoridades políticas competentes llamadas a dictar una disciplina organizativo-procedimental que especifique las formas de acceso a la PMA heteróloga y las garantías de los derechos del nasciturus.

Es precisamente sobre la perspectiva de la ineficacia de la tutela de los derechos constitucionalmente implicados — determinada en gran medida por una continua y persistente fuga del decisor político (tardía actualización de la norma técnica), así como por la persistente conflictividad ante las autoridades judiciales - que se confirma, como se ha señalado, la necesidad de una interrelación legislatio-iurisdictio. Afirmación muy divulgada y nunca cuestionada, aunque vacía y meramente retórica, si no va acompañada de la concreta definición de los alcances y las modalidades de la decisión política y de los límites de la intervención del juez, incluida la del constitucional.

Que tal aspecto constituya el verdadero nudo de la cuestión se puede deducir también del análisis de otros dos casos relacionados con las prácticas de PMA, a saber, la experimentación con embriones y la llamada sustitución de maternidad. En estos casos es importante precisar que el juez no se enfrenta a un vacío normativo, sino a una decisión prohibicionista clara y granítica tomada por el legislador. Como puede observarse, se trata de cuestiones de gran complejidad que solo se pueden aludir en esta sede recordando cómo - con referencia a la prohibición absoluta de la experimentación con embriones a que se refiere el art. 13 de la Ley núm. 40/04, tanto el Tribunal de Estrasburgo (Parrillo c. Italia, sent. 27 de agosto de 2015) como la Corte Constitucional italiana (Sentencia de 22 de marzo de 2006, núm. 84 - - han reconocido un amplio margen de apreciación para los Estados parte del CEDH y una amplia discrecionalidad del legislador. Dichas expresiones son conocidas y recurrentes, especialmente en asuntos éticamente sensibles y científicamente complejos, que, sin embargo, no permiten ser equiparados ni asimilados, siendo profundamente diferente el contexto normativo e institucional de referencia de los dos sistemas de protección de derechos.

La vigente prohibición absoluta de experimentación con embriones humanos adoptada por el legislador italiano en 2004 —según un enfoque destinado una vez más a salvaguardar instancias inespecíficas de la vida naciente, del ser humano aún en potencia- acaba por demostrar, de hecho, que no es en sí misma ilegítima, siendo justificado y oportuno predisponer una fuerte tutela respecto a la vida humana desde los primerísimos estadios de su existencia (sin perjuicio de la imposibilidad de definir con precisión e indiscutiblemente el momento en que comienza la vida humana).

Tal configuración, sin embargo, puede resultar restrictiva respecto a otros intereses de relevancia constitucional, tales como la libertad de investigación científica (arts. 9 y 33 Const.) y la tutela de la salud individual y colectiva (art. 32 Const.), que podrían beneficiarse con los resultados obtenidos a 
través de la experimentación con embriones humanos. Observándose atentamente la «elección trágica», el dilema fundamental que se debe resolver es si es razonable dar a los embriones creados con fines no experimentales, es decir con fines reproductivos y no implantados por diversas razones, un destino diferente de la crioconservación, como la recolección de células madre pluripotenciales, que si bien puede abrir nuevas perspectivas terapéuticas - no en interés del propio embrión, sino en una perspectiva solidaria-, implicaría necesariamente la destrucción del embrión.

No parece cuestionable que un destino parecido no pueda ser decidido por el juez, incluido el constitucional; lo que, en cambio, da lugar a una considerable perplejidad es que la inacción de la política para definir el destino de los embriones abandonados y no implantados excluya no solo la posibilidad de destinarlos a la investigación científica — posibilidad respecto a la cual una eventual apertura legislativa debe ir necesariamente acompañada por la predisposición de normas capaces de evitar los riesgos de la experimentación y explotación arbitrarias de los embriones-, sino también la oportunidad de que otros embriones abandonados, pero idóneos, puedan ser implantados en el útero de otra mujer dispuesta a aceptarlos y asumir la responsabilidad parental junto con su pareja (adopción de la persona por nacer), con la finalidad de satisfacer una expectativa de nacimiento y desarrollo de la vida que, en cambio, estaría inevitablemente frustrada por la prolongada crioconservación.

\section{LA CORTE CONSTITUCIONAL EN EL CONTROVERTIDO CASO DEL ABORTO}

El tema del aborto, en estrecha relación con el tema del comienzo de la vida, con sus grandes dilemas éticos, sigue siendo el centro del debate político y jurídico no solo italiano, como elocuentemente lo testimonian las recientes tensiones que en Europa interesan a España, Hungría y Polonia, pasando por el vuelco «histórico» determinado por el referéndum irlandés, sino de otras partes del mundo, como Estados Unidos y Argentina (Castano Vargas, 2018).

Para comprender los aspectos más destacados de la cuestión del aborto y en especial el aporte del juez constitucional italiano a tal fin, no podemos sino partir de la Sentencia de 18 de febrero de 1975, núm. 27, mediante la cual el juez de las leyes ha identificado por primera vez los bienes de relevancia constitucional implicados, resaltando la necesidad de una ponderación razonable entre las instancias en conflicto. La Corte Constitucional, en tal juicio, relativo al art. 546 del código penal italiano de 1930, por medio del cual se sancionaba el aborto consentido, excepto en caso de necesidad - no obstante reconociera en favor del concebido ( $y$ no ya de la colectividad nacional, como sugería la colocación del delito entre los «Crímenes contra la integridad y la salud de la estirpe»), así como en favor de la madre, intereses constitucionalmente 
protegidos-, afirmaba que la ley no puede conceder una prevalencia absoluta a uno de ellos en detrimento del otro.

Basándose en estas premisas, la Corte declaró la ilegitimidad constitucional de la disposición impugnada en cuanto no preveía que el embarazo pudiera interrumpirse, no solo en el evento del "peligro de daño grave inminente» para la vida de la mujer gestante, sino también "cuando proseguir con la gestación implique un daño o un peligro grave, comprobado médicamente [...] y no evitable de otra manera, para la salud de la madre», persona de la cual depende plenamente el concebido, quien «persona todavía debe llegar a ser».

Este pasaje de la decisión (a menudo criticado fuertemente por la doctrina) debe necesariamente leerse en forma concomitante con otros en los que la Corte no deja de enfatizar la protección necesaria de la vida por nacer, que en este caso se materializa ante todo en el deber del legislador de especificar las condiciones de peligro o daño grave para la mujer, que justifiquen el recurso a la interrupción voluntaria del embarazo (IVE) y en el deber de predisponer «criterios serios» para verificar la subsistencia de las mencionadas condiciones.

Después de la referida decisión y de un intenso debate parlamentario se aprueba la Ley de 22 de mayo de 1978, núm. 194, aún en vigor, que consiente la práctica del aborto durante los tres primeros meses de gestación cuando existan serios peligros para la salud física y psicológica de la mujer (art. 4) o, en el período sucesivo, cuando existan graves peligros para su vida o su salud. Esta ley, deliberadamente dúctil y pragmática, que recepciona el enfoque del juez constitucional, no disciplina las formas de ejercicio de un supuesto derecho al aborto, sino que marca un hito en el sistema jurídico italiano: se pasa de una perspectiva de criminalización del aborto a una perspectiva de legalización, y no a la de liberalización de tal práctica.

Los mismos postulados se confirman en otras sentencias del juez constitucional emitidas, esta vez, en el ámbito de juicios de admisibilidad de referendum abrogativos y que tenían por objeto diferentes disposiciones de la Ley núm. 194 con miras a la restauración de la normativa sancionadora anteriormente vigente o, contrariamente, con miras a la liberalización sustancial del aborto. En ellas, la Corte afirmó que algunas disposiciones de la ley que se refieren a la protección de la vida del concebido y a la salvaguarda de la salud de la mujer no pueden ser abrogadas mediante referéndum en cuanto ello conduciría a volver «nulo el nivel mínimo necesario de tutela de los derechos constitucionales inviolables», tanto de la madre como del nasciturus (Sentencias 26/81, 35/97).

No obstante la necesidad evidenciada de salvaguardar ambas exigencias: la materna y la vida naciente — todavía más inevitable habida consideración de la dependencia del nasciturus al cuerpo de la madre-, la disciplina establecida por la Ley núm. 194 ha sido sometida una y otra vez al escrutinio de constitucionalidad de la Corte, arrojando siempre resultados unidireccionales que olvidan la necesidad de hacer coexistir dentro de un sistema jurídico 
democrático y pluralista diferentes intereses de importancia constitucional, considerados en una perspectiva no absolutizante (tiránica).

Entre los variados acontecimientos judiciales en los que se cuestionó la compatibilidad constitucional de la Ley 194 se puede trazar un hilo conductor que une los diferentes casos concretos: el objeto de la disputa no es tanto la ausencia de un procedimiento dialógico eficaz y oportuno al interno de la Ley 194 —en el cual la madre pueda madurar responsable y conscientemente la dolorosa decisión de interrumpir el embarazo o de desistir de tal intención, contando de igual manera con el soporte de sujetos públicos-, sino que más bien parece querer confutar la misma capacidad de la mujer para tomar autonómamente una decisión sin necesidad de la participación en «codecisión» de un médico, del juez tutelar o del padre del concebido, llamados cada uno - con base en su propia competencia y en nombre de intereses diferentes - a verificar, controlar y participar en diferentes modos a la formación de la decisión final.

Múltiples han sido las ocasiones en las cuales la Corte Constitucional, no obstante la imposibilidad de pronunciarse en el mérito del asunto, ha interpretado la Ley precisando que «el legislador ha querido dejar — según una evaluación político/legislativa incuestionable - la responsabilidad de la decisión final de abortar en manos de la mujer», incluso en el caso de aborto de una menor de edad (art. 12), en donde se prevé la intervención del juez tutelar, en el evento en que se verifique la falta de consentimiento o la oposición por parte de quienes ejercen la responsabilidad parental. La intervención de juez tutelar, sin embargo, no confiere un poder de codecisión.

Dada la extrema claridad de la posición de la Corte, cuyo enfoque sobre el punto nunca se ha negado, sino que se ha reafirmado fuertemente en varias ocasiones, merece la pena recordar un caso más reciente que, junto con otros relacionados con el tema del aborto, son sujetos de una comparación europea. En 2012 la Corte Constitucional italiana se pronunció nuevamente sobre una cuestión planteada por un juez tutelar que conservaba dudas acerca de la compatibilidad del art. 4 de la Ley 194 con la Constitución y con el derecho de la Unión Europea a raíz de la novedad representada por la Sentencia de la Tribunal de Justicia de la Unión Europea de 18 de octubre de 2011, por medio de la cual el juez de Luxemburgo se pronunció a favor de una amplia tutela del embrión humano, desde la fase de la fecundación, con específico referimiento a la cuestión de la patentabilidad de las invenciones que implican la utilización de embriones humanos. Con Ordenanza de inadmisibilidad manifiesta de 20 de junio de 2012, núm. 196, la Corte reafirmó todos sus precedentes jurisprudenciales sobre la naturaleza del poder de autorización del juez tutelar y, sin entrar en el mérito de las relaciones con el derecho de la Unión Europea, amonestó a los jueces tutelares respecto al uso impropio e incorrecto del incidente de constitucionalidad.

Tal precisión reenvía a otra cuestión mucho más espinosa, aquella que se relaciona con la objeción de conciencia, no prevista para el juez tutelar, 
sino consentida al personal sanitario, aunque con la garantía de contar dentro de la estructura médica con otro personal que pueda llevar a cabo los procedimientos abortivos (art. 9). En cuanto a la primera cuestión, la Corte, reiterando que el juez tutelar no está llamado a verificar el cumplimiento de las condiciones de la interrupción voluntaria del embarazo (IVE), sino a pronunciarse sobre el ámbito de la capacidad del menor y, precisando que ello constituye una exigencia esencial e indeclinable del iurisdicere, ha rechazado la cuestión de constitucionalidad de la ley en la parte en que no prevé la objeción de conciencia por parte del juez.

De otro lado, respecto a la objeción de conciencia por parte del personal sanitario implicado en los procedimientos del aborto (IVE), los espacios y las limitaciones que esta tiene están en el centro de una importante decisión jurisprudencial, así como de un rico debate alimentado principalmente por la difusión incontrolada de tal objeción. Recientemente la cuestión también ha cobrado importancia supranacional, tras dos decisiones que condenan a Italia por violación de la Carta Social Europea, en particular, por violación del derecho a la salud de las mujeres en el acceso a la IVE y del derecho al trabajo de los médicos no objetores. Según el Comité Europeo de Derechos Sociales (Decisiones de 10 de marzo de 2014 y 11 de abril de 2016), las violaciones en cuestión derivan no tanto del mero hecho del alto porcentaje de personal objetor de conciencia, sino por la falta de herramientas organizativas adecuadas para garantizar la efectividad del servicio, a pesar de la presencia de los objetores.

Dicha decisión, por lo tanto, pone en tela de juicio la responsabilidad de las autoridades políticas nacionales. Su acatamiento y desarrollo en vía jurisprudencial será sin duda de gran interés, inclusive para evaluar el valor de la Carta Social Europea en el ordenamiento jurídico italiano (en este sentido las recientes Sentencias 120/2018 y 194/2018 de la Corte Constitucional).

En definitiva, es a todas luces evidente que frente a cuestiones extraordinariamente complejas como aquellas relativas al comienzo de la vida humana, la Corte Constitucional italiana ha actuado realmente como una institución fronteriza entre la política y la jurisdicción y, al mismo tiempo, entre ordenamiento interno y externo, contribuyendo de este modo al desarrollo dinámico de la Constitución y al proceso de unificación que se describe en la misma, un proceso en el que participan diferentes actores institucionales llamados a enfrentarse y a intervenir basándose en las propias competencias y responsabilidades, respecto a solicitudes que trascienden las fronteras de los sistemas jurídicos estatales.

\section{CONCLUSIONES}

Las dos «almas» de la justicia constitucional: la política y la jurisdiccional, concurren «a darle identidad y a asegurar su transmisión en el tiempo, 
convirtiéndose, sin embargo, en un mix en constante mutación, según los acontecimientos procesales y de aquello que está en juego de cada una de ellas. De modo que, sea cual sea el camino que se tome, ellas aún deben connotar, en su composición conjunta, inescindible y equilibrada, las experiencias de la justicia misma» (Ruggeri, 2016). Un justo equilibrio entre las dos, que debe renovarse continuamente, es imprescindible para evitar "tanto la "politización" de la jurisdicción como la "jurisdiccionalización" de la política» (Cheli, 1996).

El riesgo de que una u otra prevalezca — siempre muy elevado, sobre todo cuando el sistema, ante el que la Corte no es indiferente, está atravesado por fuertes tensiones político-sociales, que precisamente en las cuestiones bioéticas se manifiestan con mayor fuerza- debe ser contrarrestado precisamente utilizando las dos almas de la justicia constitucional como sus respectivos contrapoderes; de esta manera, el peligro de jurisdiccionalización de la acción política se equilibra con una judicial modesty, es decir, con la necesidad de preservar la discrecionalidad del legislador, especialmente cuando esta se logra a través de procesos abiertos, transparentes e inclusivos; y el recurso a nuevas técnicas de toma de decisiones, para decidir casos, incluso los más candentes a nivel político, debe encontrar un freno precisamente en el respeto del procedimiento, elemento típico de la jurisdicción.

En un contexto en el que las tensiones entre el poder político y el poder jurisdiccional son fuertes, es más probable una mayor exposición política del propio Tribunal Constitucional.

Por todas estas razones, el paradigma de la actuación de la Corte Constitucional italiana, y en general de todos los tribunales constitucionales, debe ser el conocimiento, la experiencia, pero también el equilibrio y la prudencia, en una palabra: la sabiduría. Los jueces constitucionales llegan a la decisión a través de un recorrido variopinto, caracterizado por un aporte plural y compuesto, como lo demuestra la misma particular composición mixta de tal órgano. No es una lógica excluyente la que mueve la acción de la Corte, sino una lógica inclusiva en la que el todo debe someterse a operaciones complejas y refinadas de ponderación y dosificación.

La prueba de tornasol del modus operandi de la Corte, y al mismo tiempo garantía de su jurisdiccionalidad, son los argumentos que sostienen las motivaciones de la decisión, los cuales no son meros contenedores de explicaciones a favor de las partes, sino que son, más bien, «comunicaciones dirigidas a la comunidad, a la sociedad, con la finalidad de explicar cuáles fueron las razones que motivaron a los jueces para haber decidido de una cierta manera». En consideración de que el objetivo de la Corte no es imponerse por la autoridad y por la fuerza, sino más bien convencer, se puede colegir que ello será aún más factible en el momento en que la confrontación dialéctica se realice en modo más transparente, inclusive a través del uso de argumentaciones de diferentes tipos. 
Es en este plano, y no más en el de la naturaleza democrático-representativa, en donde los tribunales constitucionales se juegan eternamente el partido de su legitimación.

\section{Bibliografía}

Arruego, G. (2019). Los confines del derecho fundamental a la vida. Revista Española de Derecho Constitucional, 115, 111-137. Disponible en: https://doi. org/10.18042/cepc/redc.115.04

Barbera, A. (2008). La rappresentanza politica: un mito in declino? Quaderni costituzionali, 4, 853-888.

- (2015). Costituzione della Repubblica italiana. Enciclopedia del diritto, Annali VIII. Milano: Giuffrè, 263-358.

- (2018). La Carta dei diritti: per un dialogo fra la Corte italiana e la Corte di giustizia. Quaderni costituzionali, 1, 149-174.

Bilancia, F. (2017). Etica della cura come etica pubblica. Ripensando la democrazia nel contemporáneo. En M. P. Paternò (ed.). Cura dell'altro. Interdipendenza e disuguaglianza nelle democrazie contemporanee (pp. 41-65). Napoli: Editoriale Scientifica.

Bognetti, G. (1990). La Corte costituzionale tra procedura e política. En AA.VV., Giudizio «a quo» e promovimento del processo costituzionale (pp. 221-234). Milano: Giuffrè.

Casonato, C. (2012). Introduzione al biodiritto. Torino: Giappichelli.

Cassese, S. (2009). I tribunali di Babele. I giudici alla ricerca di un nuovo ordine globale. Roma: Donzelli.

- (2017). La democrazia e i suoi limiti. Milano: Mondadori.

Castano Vargas, D. M. (2018). La procreazione medicalmente assistita. Prospettiva di bilanciamento dei diritti nell'esperienza argentina. BioLaw Journal, 3, 193-223.

Cheli, E. (1996). Il giudice delle leggi. Bologna: Il Mulino.

Chieffi, L. (2018). La procreazione medicalmente assistita nel paradigma costituzionale. Torino: Giappichelli.

D'Aloia, A. (2005). Norme, Giustizia, diritti nel tempo delle bio-tecnologie: note introduttive. En Id. (eds.). Bio-tecnologie e valori costituzionali (pp. XI-XXVIII). Torino: Giappichelli.

D'Amico, G. (2017). Le vicende della legge n. 40 del 2004 come esperienza paradigmatica del costituzionalismo contemporáneo. En S. Agosta, G. D’Amico y L. D'Andrea (eds.). La procreazione medicalmente assistita. Bilancio di un'esperienza, problemi e prospettive (pp. 29-44). Napoli: Editoriale Scientifica.

D'Andrea, A. (2017). La procreazione medicalmente assistita tra biologia e diritto. En S. Agosta, G. D'Amico y L. D'Andrea (eds.). La procreazione medicalmente assistita. Bilancio di un'esperienza, problemi e prospettive (pp. 19-27). Napoli: Editoriale Scientifica. 
- (2014). Brevi riflessioni su governance globale e costituzionalismo interlivello. Consulta online. Disponible en: http://www.giurcost.org/studi/dandrea2.pdf.

Delmas-Marty, M. (2005-6). Les forces imaginantes du droit. III. La refondation des pouvoirs. Paris: Seuil.

Dworkin, R. (1977). Taking Rights Seriously. London: Duckworth.

Ferrarese, M. R. (2010). La governance tra politica e diritto. Bologna: Il Mulino.

Fioravanti, M. (2016). Il legislatore e i giudici di fronte alla Costituzione. Quaderni costituzionali, 1, 7-20.

Frosini, T. E. (2017). Rappresentanza e legislazione nell'era della globalizzazione. Osservatorio sulle fonti, 3, 1-14.

Frosini, V. (1998). La lettera e lo spirito della legge. Milano: Giuffrè.

Husserl, G. (1955). Diritto e tempo. Milano: Giuffrè.

Laneve, G. (2014). La Giustizia costituzionale nel sistema dei poteri. I. Interpretazione e giustizia costituzionale: profili ricostruttivi. Bari: Cacucci.

- (2018). Legislatore e giudici nel contesto delle trasformazioni costituzionali della globalizzazione: alcune riflessioni. RivistaAic.it, 4, 421-454.

Longo, A. (2017). Iuxta propria principia. La Corte costituzionale tra autocomprensione identitaria, dialogo polemico tra corti e un nuovo tipo di decisione monitoria, a partire dall'ordinanza n. 24 del 2017. RivistaAic.it, 3, 1-21.

Luciani, M. (2001). Il paradigma della rappresentanza di fronte alla crisi del rappresentato. En N. Zanon y F. Biondi (eds.). Percorsi e vicende attuali della rappresentanza e della responsabilità política (pp. 109-117). Milano: Giuffrè.

- (2016a). Interpretazione conforme a Costituzione. Enciclopedia del diritto, Annali IX. Milano: Giuffrè.

- (2016b). Il costituzionalismo e l'economia dal divampare della crisi a oggi. En L. Antonini (eds.). La domanda inevasa. Dialogo tra economisti e giuristi sulle dottrine economiche che condizionano il sistema giuridico europeo (pp. 57-80). Bologna: Il Mulino.

Modugno, F. (1970). Linvalidità della legge. Milano: Giuffrè.

Morrone, A. (2014). Ubi scientia ibi iura. A prima lettura sull'eterologa. Forumcostituzionale.it. Disponible en: https://bit.ly/31vrrZ8.

- (2016). Globalizzazione e trasformazioni costituzionali. En AA.VV., Scritti in onore di Gaetano Silvestri (pp. 1471-1485). Torino: Giappichelli.

- (2019). Suprematismo giudiziario. Su sconfinamenti e legittimazione politica della Corte costituzionale. Quaderni costituzionali, 2, 251-290.

Onida, V. (2006). Una nuova frontiera per la Corte costituzionale: istituzione di 'confine' fra diritto nazionale e sovranazionale. En N. Zanon (ed.). Le Corti dell'integrazione europea e la Corte costituzionale italiana (pp. 533-538). Napoli: Edizioni Scientifiche Italiane.

Pintore, A. (2017). Il desiderio dei diritti. Rivista di fllosofía del diritto, 2, 231-252.

Romboli, R. (2017). Le oscillazioni della Corte costituzionale tra l'«anima» politica e quella "giurisdizionale». Una tavola rotonda per ricordare Alessandro Pizzorusso ad un anno dalla sua scomparsa. En Id. (ed.). Ricordando Alessandro Piz- 
zorusso. Il pendolo della Corte. Le oscillazioni della Corte costituzionale tra l'anima 'politica' e quella 'giurisdizionale' (pp. 1-39). Torino: Giappichelli.

Ruggeri, A. (2007). Teorie e 'usi' della Costituzione. Quaderni costituzionali, 3, 519540.

- (2011). Ripensando alla natura della Corte costituzionale, alla luce della ricostruzione degli effetti delle sue pronunzie e nella prospettiva delle relazioni con le Corti europee. En R. Balduzzi, M. Cavino y J. Luther (eds.). Corte costituzionale vent'anni dopo la svolta (pp. 349-373). Torino: Giappichelli.

- (2016). Teoria della Costituzione e tendenze della giustizia costituzionale. Al bivio tra mantenimento della giurisdizione e primato della politica. Federalismi. it, 25, 2-28.

- (2018). Crisi della rappresentanza politica e «Stato giurisdizionale» (nota minima su un'annosa e irrisolta questione). Federalismi.it, 23, 2-20.

Scaccia, G. (2017a). Constitutional Values and Judge-Made Law. The Italian Law Journal, 1, 177-191.

- (2017b). Giudici comuni e diritto dell'Unione europea nella sentenza della Corte costituzionale n. 269 del 2017. Giurisprudenza costituzionale, 6, 29482955.

Schmitt, C. (1978). Die Legale Weltrevolution: Politischer Mehrwert als Prämie auf juristische Legalität und Superlegalität. Der Staat, 3, 321-339.

Serges, G. (2017). Crisi della rappresentanza parlamentare e moltiplicazione delle fonti. Osservatorio sulle fonti, 3, 2-21.

Staiano, S. (2017). Rappresentanza. En AA.VV., Di alcune grandi categorie del diritto costituzionale. Sovranità Rappresentanza Territorio (pp. 267-328). Napoli: Jovene.

Tripodina, C. (2012). Nascere e morire tra diritto politico e diritto giurisprudenziale. En M. Cavino y C. Tripodina (eds.). La tutela dei diritti fondamentali tra diritto politico e diritto giurisprudenziale: "casi difficili» alla prova (pp. 41-82). Milano: Giuffrè.

Urbinati, N. (2013). Democrazia in diretta: le nuove sfide alla rappresentanza. Milano: Feltrinelli.

Zanon, N. (2015). Pluralismo dei valori e unità del diritto: una riflessione. Quaderni costituzionali, 4, 919-930.

Zanuso, F. (2015). Diritto e desiderio. Riflessioni biogiuridiche. Milano: Franco Angeli. 